\title{
Motion in Place: a Case Study of Archaeological Reconstruction Using Motion Capture
}

\author{
Stuart Dunn \\ King's College London, UK. stuart.dunn@kcl.ac.uk
}

Kirk Woolford, Leon Barker, Milo Taylor, Sally Jane Norman, Martin White

University of Sussex, UK.

Mark Hedges

King's College London, UK.

Helen Bailey

University of Bedfordshire, UK.

Michael Fulford, Amanda Clarke

University of Reading, UK.

\begin{abstract}
:
Human movement constitutes a fundamental part of the archaeological process, and of any interpretation of a site's usage; yet there has to date been little or no consideration of how movement observed (in contemporary situations) and inferred (in archaeological reconstruction) can be documented. This paper reports on the Motion in Place Platform project, which seeks to use motion capture hardware and data to test human responses to Virtual Reality (VR) environments and their real-world equivalents using round houses of the Southern British Iron Age which have been both modelled in $3 D$ and reconstructed in the present day as a case study. This allows us to frame questions about the assumptions which are implicitly hardwired into VR presentations of archaeology and cultural heritage in new ways. In the future, this will lead to new insights into how VR models can be constructed, used and transmitted.
\end{abstract}

Key Words: Motion Capture Data, Reconstruction, Virtual Reality, Experimental Archaeology

\section{Introduction}

Experimental archaeology is often cited as an important asset in the study of human interaction with material culture, especially in remote periods of history where there are few other sources of data on the humaninterventions which constitute the archaeological record. This has found many expressions in the discourse of archaeological theory, including the so-called chaîne opératoire, or 'operational sequence' theory (see e.g. Bar-Yosef and Van Peer 2009). However, due to an understandable desire to adhere to empirical evidence, means of inferring the human movement behind those interventions are rarely considered in the computational reconstruction of archaeological environments. The most obvious reason for this is that buildings, features and artefacts can be understood and reconstructed (whether digitally or not) from empirical archaeological remains, whereas there is little or no direct evidence for how people might have looked and moved through the spaces they created. Approaches which seek to go beyond this 
are methodologically fraught, resulting in a limitation of the scope of $3 \mathrm{D}$ reconstruction, both as a tool for archaeological research and as means of presenting cultural heritage to the public. The impact on the user's experience of those reconstructions is also limited. In a review of $3 \mathrm{D}$ visualization in archaeology, Gillings states: '[I]t is worth noting that one of the most striking things about archaeological Virtualmodels is the lack of people in them. As a result, wandering around re-creations such as VirtualStonehenge can be a ghostly and unsettling experience' (Gillings 1999). It is also worth observing that such previous research as has been done on the application of human motion in reconstruction has typically focused on what might be termed 'extra-ordinary' activities, such as ritual (e.g. Farvo and Johanson 2010). There remains a lack of consideration, and theory, of how day to day practices can be visualized and presented as products of human activity.

This paper describes the Motion in Place Platform, a year-long Arts and Humanities Research Council Funded project to study uses of motion capture hardware outside the studio (see http://www.motioninplace.org, last accessed 30/11/2011). Two connected sets of experiments in combining captured human movement with physical and virtual archaeological environments were designed. In the first, bespoke motion capture hardware was employed to overlay motion from human actors performed in a studio into a virtual reconstruction of Iron Age dwellings. Using specially adapted motion capture apparati, the project developed and represented a set of day to day activities that may be conjectured to have taken place within a round house of the southern British Iron Age, the dimensions of which were determined from the outline of such a structure uncovered at the site of Silchester in Hampshire, England (Clarke et al. 2007). These representations were first performed by professional artists in a studio and integrated directly into a digital $3 \mathrm{D}$ model based on the Silchester round house, developed using a combination of Autodesk Maya and the Unity $3 \mathrm{D}$ game engine. The model was designed, illustrated and textured in collaboration with the Silchester archaeological team.

The second experiment was carried out in collaboration with the Butser Ancient Farm in Hampshire, England (see www. butserancientfarm.co.uk), where capture of the same set of tasks was carried out in a round house reconstructed from excavation data from Moel y Gerddi, Wales (see http://www. butserancientfarm.co.uk/pdf/moel\%20y\%20 gerddi\%2oguide.pdf). This allowed us to test human reactions to the physical environment. In this, actors (students and performers) who are not familiar with the physical environment were motion captured carrying out the same tasks, as was an experimental archaeologist who has extensive experience of the environment. We were thus able to document and visualize if nothing else - how the addition of experience of a place changes approaches even to the most basic of tasks in a material context, such as sweeping and grinding corn.

The purpose of this project was not to try to reenact inferred or probable scenarios of Iron Age life, nor was it to draw direct parallels between the experiences of modern humans and their Iron Age counterparts. Rather, the aim was to test possible uses of domestic environments in a material context using motion data visualization and to understand better how people react when performing the same tasks in real and virtual environments; and what role factors such as experience plays in this. It is, in other words, a virtual extension of wellestablished (but not universally accepted) means of reconstructing paleoenvironments using experimental methods (Coles 1979; Reynolds 1993).

\section{Aspects and Uses of Motion Capture}

Data derived from motion capture hardware can take numerous forms. Principally, but not 
exclusively, it can appear as flows of people represented on a map or as wireframes of the human form animated using data from the sensors on a motion capture suit. These can be classified, after Moeslund et al. (2006) in to broad categories of surveillance, control and analysis. Surveillance is the observation of the behaviour of individuals and/or crowds; for example for public order at sports grounds. Control is where a human uses a piece of hardware to direct action in a virtual environment (such as a game). Analysis is where motion capture is used to build and/ or augment other forms of information, particularly the annotation of video and motion traces (Moeslund et al. 2006). The simulation and documentation of different forms of (human) activities that constitute potential operational sequences in both past and present environments falls chiefly in to the category of analysis. While this has been investigated previously (Tang and Liu 2002), many such approaches are purely representational, tending to avoid the pressures that integration of motion capture data with $3 \mathrm{D}$ environments places on interpretation. This is a key factor limiting the uptake of 3D methodologies in archaeology and cultural heritage, even as motion capture and animation technologies become cheaper and more readily available than ever before.

Another area is the potential role which motion capture technologies have to play the public presentation and consumption of heritage. Mainly, one suspects, for reasons of cost, digital reconstructions of the past containing humans have been largely (but not wholly) confined to commercial film sets. There is a distinction between constructivist approaches to the presentation of archaeological and heritage sites, where the public are encouraged to engage with the interpretative process, for example by being presented with alterative viewpoints and questions; and positivistic approaches, where a single 'photorealistic' representation of reality - or rather what the archaeologist believes reality might have looked like - is presented
(Copeland 2004). By presenting different scenarios documented in motion capture, we have to potential to present audiences with different possibilities of how a space was used, and expose those possibilities to different interpretations.

These questions are complex, and touch on numerous disciplines, including the understanding and representation of space in archaeology, animation, 3D rendering, and the treatment and documentation of artefacts (Bodenhamer 2010). More than this however, the MiPP project sought to consider immersive $3 \mathrm{D}$ environments combined with motion capture technology in the context of the theory and practice of experimental archaeology. Archaeological evidence is, and always has been, primarily about material, and about what the process of human existence has left in the ground for us to find and document empirically. Experimental archaeology seeks to evaluate the methods (although not necessarily the tools) used to create features such as buildings and artefacts, such as arrowheads, with the evaluations derived from empirical evidence (Coles 1979). Careful observation and recording of the construction and creation processes can lead to new insights in to how buildings and artefacts were created and in some cases can help explain anomalous or unusual features in the material record. For example, the presence of curved depressions in the ground near the structure of the round house at Pimperne Down, Dorset, had no apparent function or relationship with the building whatsoever. In the process of reconstructing this round house at the Butser Ancient Farm experimental archaeology site, it was found that such depressions are made when manoeuvring the structure's roof beams in to place (Reynolds 1993).

\section{The Limitations of Reconstruction and 'Intangible Cultural Heritage'}

Implicit in all archaeological interpretation is the truth that 'the human factor' is behind the 
process of the material record's creation; and 'the human factor' is precisely what motion capture is able to bring to virtual reconstruction. However, human processes have, in the past, been regarded as intangible and unrecoverable and are therefore implicitly and explicitly written off in experimental archaeology. This is reflected in global regulatory practices on 'intangible cultural heritage' which UNESCO considers protectable alongside tangible heritage (such as the Great Wall of China) and natural heritage (such as the Amazon basin). Intangible cultural heritage encompasses language, oral traditions, practices transmitted by gesture, music etc. Recent governance models seek to sustain traditions which are extant by supporting those who practice and transmit them: "not only the masterpieces but also the masters" (Kirshenblatt-Gimblett 2004). When one is dealing with pre-literate societies, such as the British Iron Age, there are of course no individual 'masters' to whom cultural practices can be traced. There is therefore a tension in the reconstruction, as opposed to the preservation of ancient intangible heritage. These traditions are 'dead', and therefore not 'preservable'. For this reason, experimental archaeologists have traditionally shunned 'the human factor', focusing instead on the re-creation of archaeological features from empirical evidence (Coles 1979; Harding 2009). Indeed, the very notion of attempting to include 'the human factor' in experimental reconstructions is viewed with scepticism at best and outright hostility at worst. As Peter Reynolds, the founding director of the Butser Ancient Farm project has put it:

"In real terms it is only sensible to examine structures physically and as far as possible to dehumanise the examination process. Reenactment is best left as a dramatic indulgence to the imagination, which can be recognised as singularly valueless and instantly forgettable ... History, and by implication prehistory, is swiftly becoming a tabloid newspaper subeditor's view of the past" (Reynolds 1993).
While some might view the strength of this distinction between the academic and the educational as being somewhat harsh, it nonetheless highlights a significant gap not only in 'real world' reconstruction projects such as Butser but also, as we shall see, in the application of virtual reality reconstruction itself.

\section{Layout of Round Houses}

The geometries and spatial footprints of most round houses of this period are determined from the configuration of the postholes left by the beams which supported their structures (Harding 2009; Reynolds 1993). In these layouts, the doorway is most often aligned towards the south east i.e. towards the rising sun. Previous surveys of the configuration of finds within round houses have identified a recurring pattern, in which most finds associated with domestic activity are located in the right-hand (southern) section of the structure, whereas the left-hand (northern) section is largely devoid of finds (Webley 2009). This pattern has led to a general interpretation that the right hand section, which, given the south-easterly orientation of the doorway would have received most sunlight, was the domestic area, given over to activities such as grain grinding, cooking, weaving, washing etc. whereas the northern half of the building was given over to activities such as sleeping. It has been noted that such a division of space would have made the best use of the daylight as the sun proceeds along its parabola: the so-called 'sunwise' model of roundhouse occupation (Fitzpatrick 1994). However, many of these finds, chiefly ceramics, occur in the post holes themselves with many pieces, including large shards, being tightly packed in to the shafts. This led Webley (2009) to suggest that the northsouth find pattern is caused by some formal practice of abandonment and destruction of the buildings at the end of their occupation periods, rather than day to day activities during it. This possibility being present, we decided 
not to explicitly integrate the sunwise model into the representation developed; although this is something we are likely to revisit in more detail in future stages of the project.

\section{Experiment 1: Modelling Motions in Virtual Environments}

MiPP's first experiment was the construction of a virtual round house, and its population, in a studio, of motion capture derived from persons tasked with certain actions. As noted above, this started with a hypothetical Iron Age roundhouse, derived from the Roman urban excavation at Silchester (Clarke et al. 2007; Fig. 1). The physical evidence for this feature is not extensive, comprising in the main of a circular impression where the wall rested. Inferring evidence for the types of materials used was relatively straightforward, as the materials from previous constructions had been deposited into the ground. However the shape of the structures could not be evidenced in the same way and had to rely upon the interpretation of the archaeological record. Guided by illustrations and photographs of comparable structures the building was modelled and textured (Figs 2 and 3).

Given that round houses were domestic settings, it was determined that these actions should be day to day activities, with the actions themselves being based as far as possible on available evidence from elsewhere. The first step in this process was to develop $3 \mathrm{D}$ character models, which is a critical step in the process of simulating the activities of human agents. Utilising 3D modelling tools including Maya, 3Ds Max and Zbrush we started to model characters (Fig. 4). Once the characters had been modelled, two dancers were tasked to explore and participate in the type of tasks that might have been performed during the daily activities of inhabitants. The choice of activities was derived from the discussion of finds in Webley 2009 and Harding 2009; and also from discussions with staff at the

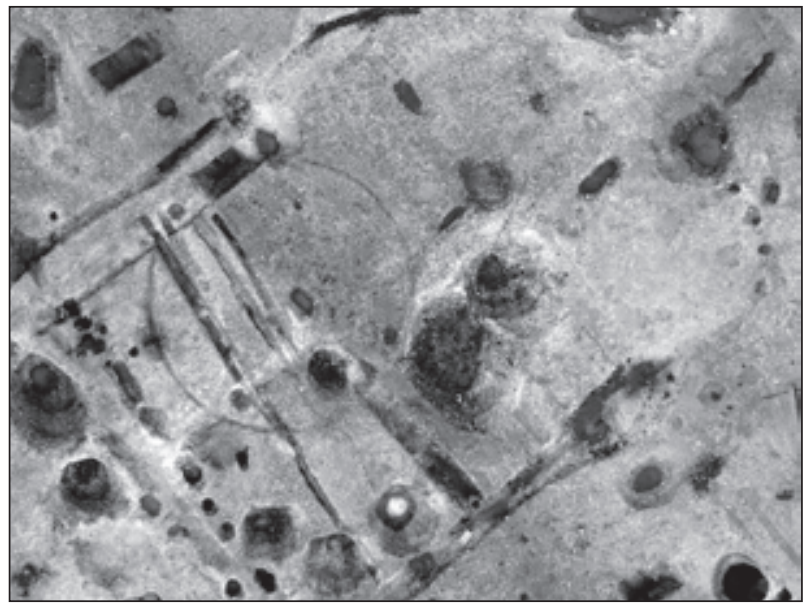

Figure 1. Impression of round house at Silchester, Hampshire.

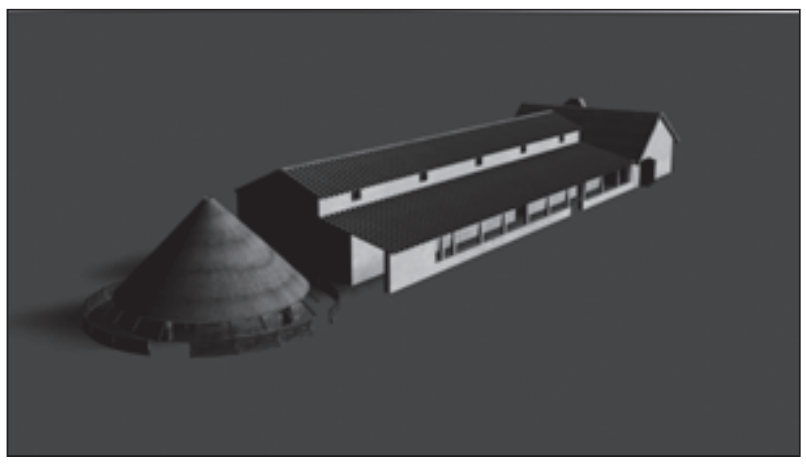

Figure 2. Reconstructed Iron Age roundhouse and subsequent Roman buildings.

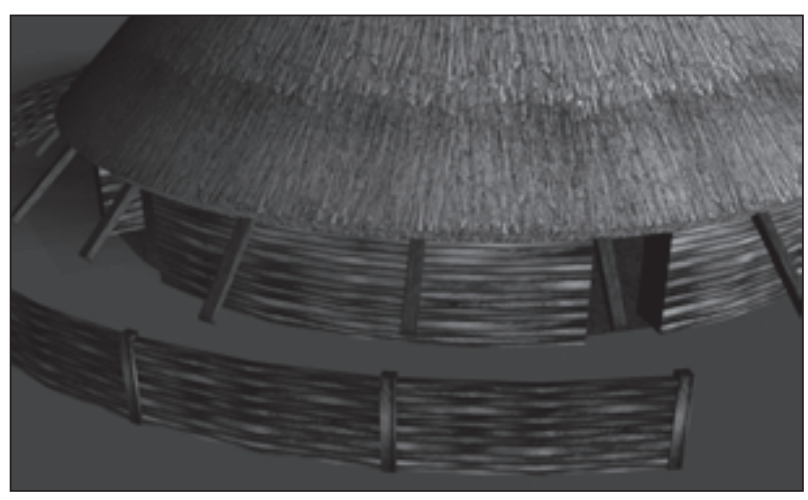

Figure 3. Reconstructed round house.

Butser Ancient Farm and included sweeping, cooking and lifting water from a nearby well. In order to correctly constrain these activities spatially, an area of floor space in a studio at the University of Bedford was taped out with 


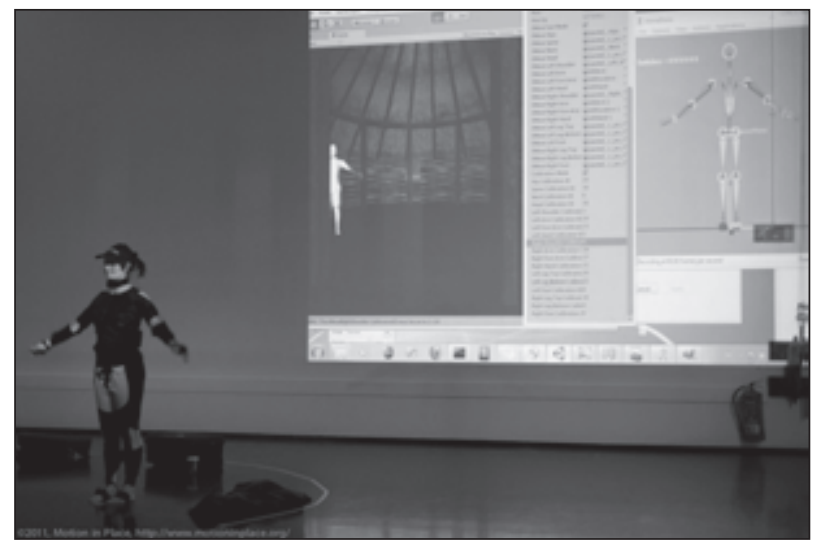

Figure 4. Realtime capture in a virtual environment using Animazoo/Sussex eMove tools.

dimensions equivalent to the Silchester round house (Fig. 5). During the performance of the tasks, participants wore Animazoo IGS190 inertial motion capture suits enabling their physical actions to be recorded. This motion was mapped, in real-time, into the virtual $3 \mathrm{D}$ round house (Fig. 6) using Unity3 D and a suite of software tools developed as part of the eMove project: a joint research project between Sussex informatics department and Animazoo (http://www.mocapsuit.com). The data was simultaneously saved in Biovision Hierarchy (bvh) format so the resulting motion data could be subsequently analysed and/or attached to a character model for further animation.

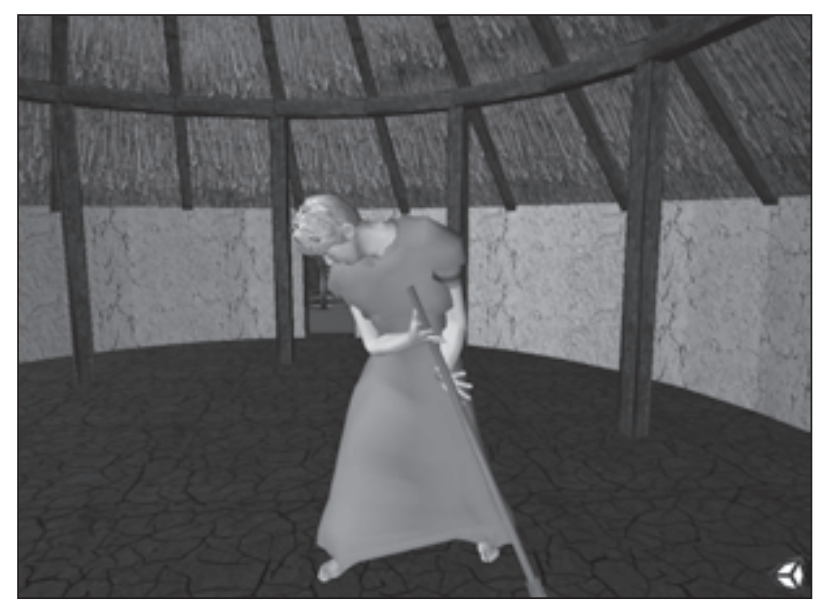

Figure 6. The motion data mapped onto a realtime virtual character in Unity $3 D$.

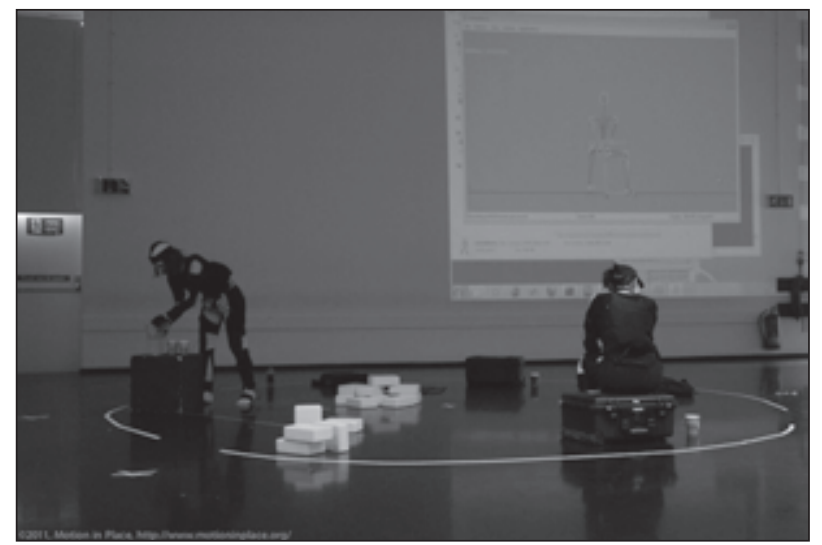

Figure 5. Studio based reconstruction of round house activities.

This studio-based approach to modelling movement demonstrated the importance of provenance and the need to document assumptions made during the motion capture. When one of the dancers was asked to sweep the virtual roundhouse, she used a modern push broom and began to move as she would normally sweep the studio. After she was reminded that the push broom was a 2oth century invention which would not have existed in a round house, the dancer swung the broom from side-to-side without touching the floor. Neither of these sweeping actions could be considered "correct".

\section{Experiment 2: Direct Capture in situ}

The first experiment showed that the connection to material objects such as tools and buildings were of crucial importance to the project so a further set of experiments was devised around the tasks of sweeping, working with a (re) construction of an Iron Age broom both within a studio, as well as in a (re)constructed round house. Two dancer/choreographers were given this broom to sweep in the virtual round house as well as the physical round house. In the virtual round house, their movements had no consequence. In the physical round house, they learned that large, fast movements not only failed to clear the floor, but also created dense clouds of dust and damaged the floor of the house. The dancers' movements were 
then compared with the movements of an experimental archaeologist who worked in the house on a daily basis performing the same task. Other daily activities including grinding grain with a quern, fetching water and making bread, were all captured both with props in the studio, and with (re)constructed artefacts in the round house. The use of motion capture technologies allowed the research team not only to capture motion data for visualization, but to analyse the difference in movement dependent upon the artefact, environment and the experience of the user. Figures $8 \mathrm{a}$ and $8 \mathrm{~b}$ show respectively an inexperienced user and the experimental archaeologist operating a quern stone for grinding corn. It is plain to see that, in $8 \mathrm{~b}$, there is a far clearer and more consistent set of motions, along with clear clues as to the object's most efficient usage: the employment of a circular motion on the quern stone rather than the back-and-forth motion of the inexperienced user. This is, in effect, an extension of experimental archaeology, which allows us to infer how people are likely to have interacted with their physical environments as well as how those environments (or tools) were constructed.

\section{Discussion and Future Work}

As noted, the purpose of this exercise is not to attempt to re-enact possible scenarios of history or prehistory, but to capture and visualize human interaction with material culture as documented by archaeological evidence. As far as we are aware, this is the first attempt to link explicitly a remediated VR with the 'real world' by human agency as represented by empirical motion capture data. In this paper, we have attempted to set out the limitations that undoubtedly exist in reconstructing and visualizing human agency but believe that, within those limitations, this approach has a contribution to make to the development of VR models in archaeology and in understanding and experiencing archaeological locations. We used the 'photorealistic' $3 \mathrm{D}$ model only as a

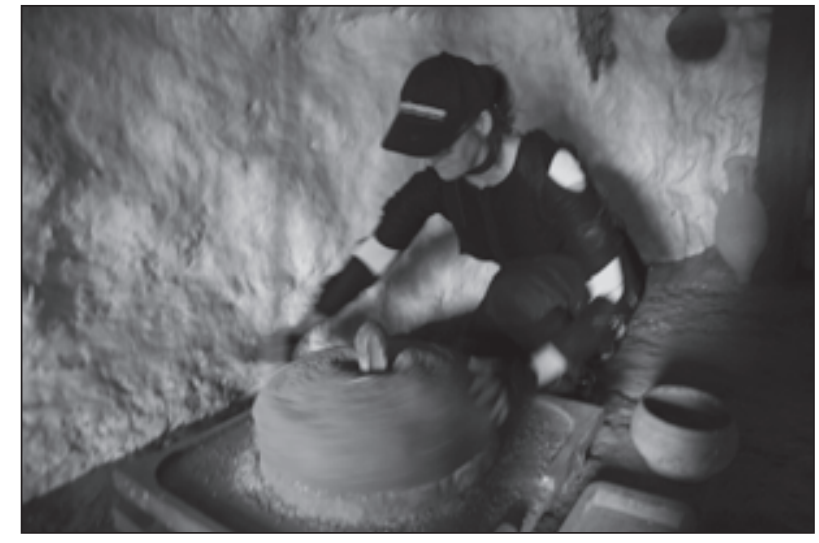

Figure 7. Moel y Gerddi round house at Butser Farm.

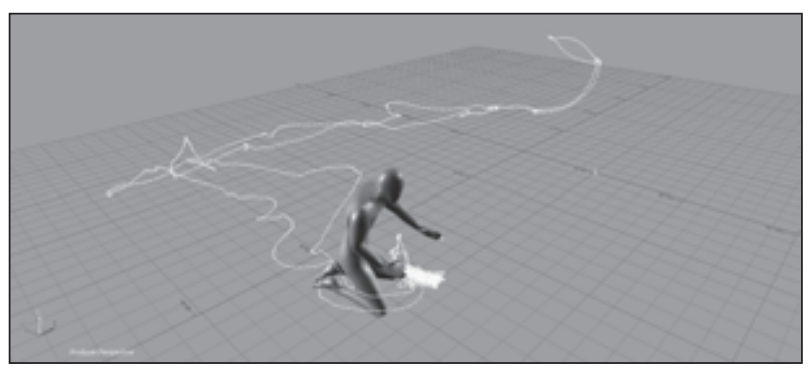

Figure 8a. Inexperienced operator using quern.

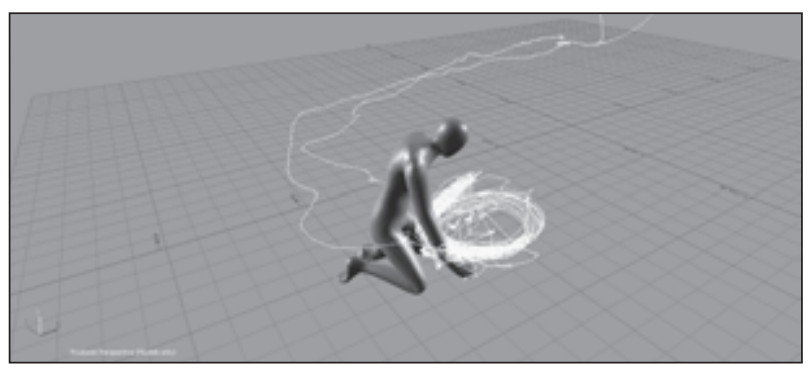

Figure 8b. Experienced operator using quern.

backdrop to provide visual context.

During the capture process, we became aware that we were making numerous assumptions about motion which we needed to record in order to provide a context for our motion data. For example, when capturing in the studio, we became aware of how much the hard floor and dancer's shoes constrained the movement, so we replicated the motions barefoot, outdoors on uneven grass. We realised how much external factors such as footware, clothing, training, 
experience, age and gender of the mover impacted the motion data. Many assumptions of this kind are either overlooked altogether, or implicitly encoded into photorealistic $3 \mathrm{D}$ models, of which the round house we produced is an example. While we cannot remove such assumptions from the reception and transmission of VR environments, our motion capture trials using the model have allowed us to begin to isolate and critically assess them.

It became clear that one key factor missing from our reconstruction of the hypothetical tasks is the ability to annotate and describe the motion data objects. The key difference between the kind of 'human factor' representations and re-enactments that are currently viewed with suspicion by experimental archaeologists is that digital capture should allow particular actions and particular temporal points in each trace to be labelled with a) what material evidence relates to each action or trace, or b) if there is no material evidence, what that action has represented. Mark-up is commonplace in other kinds of data formats. The TEI has spawned several subsets for specific areas, such as EpiDoc for marking up epigraphic data (http://epidoc.sourceforge.net), and markup languages for $3 \mathrm{D}$ modelling (e.g. VRML) are well developed. Especially against the background of a field such as archaeology, where there are already highly developed information recording and presentation conventions, marking up quantitative representations of immaterial events should be easy. One example might be to assign levels of certainty to various activities; in much the same way that textual mark-up allows editors to grade the scribal or editorial certainty of sections of text. It should be possible, for example, to state that 'we have $100 \%$ certainty that there were activities to do with fire in this room because there is a hearth and charring, but only 50\% certainty that the fire was used for ritual activity'. It should also be possible to develop a system for citing archaeological contexts in support of particular types of activity.

\section{Conclusions}

The MiPP project sought to replicate contemporaneously the actions that the evidence suggest was carried out in a round house, document those using motion capture technologies, and to use these. The approach has the potential to bring to life not only the round house, but the kind of things those inhabiting it would have done. At the same time, we believe our work to date has demonstrated the potential for new ways of critically assessing and using VR models in archaeology and cultural heritage.

The theoretical questions this raises about how $3 \mathrm{D}$ visualization can - and the degree to which it should - impact on our perception of the ancient world are far-reaching. Archaeology is fundamentally about the material record: tracing what has survived in the soil and building theories top of that. Since the eighteenth century, Britain's museums have operated on, and extended, the same principle: they are polished presentations of the 'final' material record. However, many of our theories concern what people did, and where and how they moved while they were doing. We have reconstructed in a practical and agentive way how certain everyday tasks might have been accomplished by the Iron Age inhabitants and further development of the project will seek to refine and formalize the evidence framework in which this rests. Reconstructions such as this are not reconstructions in the normally accepted sense in archaeology, where the focus is usually on visual, architectural and formal remediation of buildings (as excellently done already by the Silchester project). However, we believe that they will prove themselves to be powerful stimuli for further archaeological research questions, as well as for public engagement and contemporary reception of Iron Age life.

\section{Acknowledgements}

We would like to thank the staff at Butser Ancient Farm for permission to undertake 
CAA2O11 - Revive the Past: Proceedings of the 39th Conference in Computer Applications and Quantitative Methods in Archaeology, Beijing, China, 12-16 April 2011

capture work there in 2011 and for their advice throughout the later stages of the project.

\section{Bibliography}

Bar-Yosef, O., and Van Peer, P. 2009. "The Chaîne Opératoire Approach in Middle Paleolithic Archaeology." Current Anthropology 50 (1):103131.

Bodenhamer, D. J. 2010. "The potential of spatial humanities." In The spatial humanities. GIS and the future of humanities scholarship, edited by D. J. Bodenhamer, J. Corrigan, and T. M. Harris, 14-30. Indiana University Press.

Clarke, A., Fulford, M. G., Rains, M., and Tootell, K. 2007. "Silchester Roman Town Insula IX: The Development of an Urban Property c. AD 40-50 - c. AD 250." Internet Archaeology 21.

Coles, J. M. 1979. Experimental Archaeology. London: Academic Press Inc.

Copeland, T. 2004. "Presenting archaeology to the public: constructing insights on-site." In Public archaeology, edited by N. Merriman, 132-144. London/New York: Routledge.

Farvo, D., and Johanson C. 2010. "Death in Motion: Funeral processions in the Roman Forum." Journal of the Society of Architectural Historians 69 (1):1237 .

Fitzpatrick, A. 1994. "Outside in: The structure of an Early Iron Age house at Dunston Park, Thatcham, Berkshire.” In The Iron Age in Wessex: Recent work, edited by A. Pitzpatrick and E. Morris, 68-72. Salisbury.

Gillings, M. 1999. "Engaging place: a framework for the integration and realisation of virtual-reality approaches in archaeology." In Archaeology in the Age of the Internet. Proceedings of the 25th Computer Applications and Quantitative Methods in Archaeology University of Birmingham, April 1997, edited by L. Dingwall, S. Exon, and V. Gaffney,
247-254.

Harding, D. W. 2009. The Iron Age round-house: later prehistoric building in Britain and beyond. Oxford: Oxford University Press.

Kirshenblatt-Gimblett, B. 2004. "Intangible heritage as metacultural production." Museum International 56 (1-2):221-222.

Moeslund, T. B., Hiltonb, A., and Krüger, V. 2006. "A survey of advances in vision-based human motion capture and analysis." Computer Vision and Image Understanding 104 (2-3):90-126.

Reynolds, P. 1993. "Experimental reconstruction. The report of a specific construction based upon the excavation of a great roundhouse at Pimperne Down in Dorset, including an account of the life of the structure and its final dismantlement." In An Iron Age settlement in Dorset: excavation and reconstruction. Edinburgh: Edinburgh University Monograph.

Tang, S. K., and Liu, Y. T. 2002. "A digital reconstruction procedure for a disappeared city space and its activities." In Proceedings of the Twentieth Conference on Education in Computer Aided Architecture Design in Europe. 598-603.

Webley, L. 2009. "Using and abandoning roundhouses. A reinterpretation of the evidence from late Bronze Age-Early Iron Age Southern England." Oxford Journal of Archaeology 26 (2):127-144. 